\title{
The relative value of fire planning alternatives
}

\author{
D. B. Rideout \& N. Kernohan \\ WESTFIRE Research Center, \\ Department of Forest and Rangeland Stewardship, \\ Colorado State University, USA
}

\begin{abstract}
Assessing the value of fire planning alternatives is challenging because fire affects a wide array of ecosystem, market, and social values. Pragmatic approaches to assessing the value of fire management are yet to be developed. Previous approaches to assessing the value of forest management relied on connecting site valuation with management variables. While sound, such analysis is too narrow to account for today's broader ecosystem services. Ecosystem management brought the design of fire regime condition class but it is entirely biophysical. Its void of economic information cripples its utility to support decision-making. By focusing on marginal analysis and the value of improvement obtained by fire management, we define and present a means of assessing the deviation of a landscape from its desired fire management condition. Using a case study site in Colorado, we displayed the deviation across a landscape and summed the deviations to produce a summary metric. This summary metric was used to assess the value of alternative fire management strategies on improving the desired fire management condition. It enabled us to identify which sites are most valuable to restore, even if they are in the same fire regime condition class. The case study site exemplified how a wide range of disparate values can be incorporated such as watershed, wildlife, property and timber. Positive deviations in the landscape from desired condition present opportunities for improvement or restoration through fuels treatment and negative deviations present opportunities for improvement through fuel efforts such as suppression.
\end{abstract}

Keywords: landscape analysis, wildland fire, spatial planning, watershed, desired condition, condition class, fire regime condition class, economics. 


\section{Introduction}

Assessing the value of management alternatives on natural ecosystems has long challenged resource professionals. This lengthy and difficult problem has seen few economically credible solutions. Solutions date back at least to the classic work of Martin Faustmann [1] who, by using a discounted cash flow analysis, made perhaps the first analytically correct assessment of the value of a natural system devoted to commercial forest yields. By estimating the present value of timber yields on a perpetual basis, he established the value of the underlying capital asset (forestland). His approach was confirmed and elaborated upon by Nobel Prize winning economist, Paul Samuelson [2] who clarified the relationship between changes in management and changes in the capital asset. Faustmann, Samuelson and others engineered the early approaches to valuing natural systems and to the relationship between management variables and the capital value of natural ecosystems. Today's fire planning is expected to be purposeful with respect to full range of values including the protection of life and property, and the restoration and maintenance of ecosystem values. However, the linkage between management variables and the value of the underlying natural capital is yet to be soundly addressed. The solution calls for addressing the complex interactions between nature's services, management alternatives, and the value of environmental capital.

With public land management embracing ecosystem management in the 1990 s, a broad set of complex ecosystem values were to be addressed. With no pragmatically viable economic methodology for relating ecosystem value to management alternatives, the "Committee of Scientists" [3] in 1999 proposed to use and measure a particular ecosystem's departure from a baseline or reference condition as a foundational concept. Restoration would be required to bring the ecosystem back to the baseline condition. Hardy et al. [4] and Hann and Bunnell [5] introduced current "condition class" that was later refined by "fire regime condition class" assessment system (FRCC) in 2003. The concept of condition class is to measure the departure of the current ecosystem condition from a reference condition. FRCCs currently range from one to three with maximum departure in class three. It is important to note that CC and FRCC are metrics estimated entirely on underlying biophysical conditions. Consequently, they omit the economic content essential to guide cost-effective allocations of scarce resources. Hardy et al., made a similar statement. Nevertheless, FRCC is often suggested as a decision criterion where ecosystem restoration is a planning objective. "For example, planners will use the Current Condition Class data to allocate resources for fire and fuel management" [4], but FRCC cannot resolve this allocation issue because funds are available to restore only a small portion of the landscape.

In this context, implicitly assuming that lands in poor condition such as FRCC 3, would be restored to a more desirable condition, such as FRCC 1, fails to address the important reality that restoration values differ. Assume two areas where one is predominantly ponderosa pine and the other is primarily sequoia and both are classified as FRCC 3. If funds are available to only restore one of 
them, then FRCC provides no guidance as to how to allocate management resources. This simple example is symptomatic of the larger issues of implicitly using FRCC as a proxy for site value. The advent of ecosystem management, that made narrow measures of site value [1] and [2] largely irrelevant for such purposes, and its call for restoration remains largely void of economically viable approaches that relate management variables to ecosystem condition.

In-between the narrow, but remarkable work of Faustmann and the introduction of the restoration paradigm was the era of multiple use. Multiple use expanded the value set beyond timber to include other use values such as grazing and water. Mills and Flowers [6] discussed the concept of Net Value Change (NVC) for use in fire management. NVC is a straightforward and sound concept: estimate the value of the ecosystem before and after a fire event and this difference will identify the economic impact of the fire. During the multiple use era calculating NVC had pragmatic appeal because use values and their impact on the asset value change could, in principle, be measured. But this has not been the case for ecosystem management and the restoration paradigm with its broad value set that includes public goods [7].

If the first step to resolving the valuation problem is admitting that measuring the value of an ecosystem is not pragmatically viable, perhaps the second step is recognizing that FRCC or CC, is not a viable proxy for site value and it cannot guide cost-effective resource allocation decisions. We start with the notion that today's management alternatives and their affect on ecosystem values is more complex. Sound land and fire management planning addresses the full range of values including life and property, market and non-market resources, and public goods to be viable. This includes nature's services, some of which are market driven, such as commercial timber or tourism and some are what economists call "public goods" (and other related categories such as merit goods) such as air quality or scenic views where one person's enjoyment does not detract from another person's enjoyment. It must also address restoration as a management activity related to ecosystem management. This broadening of values is compounded by the fact that a single wildland fire often engages a wide range of resource values.

Since no credible approach for measuring the effect of management on ecosystem value has emerged, we return to the early analysis of Faustmann as a foundational concept. Faustmann, as enhanced by Samuelson, showed that changes in management variables, such as timber rotation lengths, were directly tied to changes in the value of the underlying environmental asset. This can be expressed in the context of maximizing the value of the asset (V) as a function of management variables $(\mathrm{M})$ :

$$
\operatorname{MAX}(V)=f\left(M_{1}, M_{2}, M_{3, \cdots}\right)
$$

where "f" denotes a continuous function of management effects on asset value. The management variables, applied at different intensities, alter the flow of 
environmental services to change V. Maximizing the value of the ecosystem condition requires that the first order condition of (2) be zero:

$$
\frac{\partial V}{\partial M_{1}}=0
$$

In (2), management variable $\mathrm{M}_{1}$ is applied such that increasing or decreasing its application cannot improve the asset value. Satisfying (2) means that $\mathrm{M}_{1}$ has been applied until its marginal value is zero; a condition that is optimal only if management is free. Nevertheless, (2) provides a conceptual benchmark analogous to today's statements regarding desired ecosystem condition.

Equation (2) provides an economic reference condition for defining desired condition and for defining departures from desired condition. Assuming " $\mathrm{f}$ " is monotonically increasing to a maximum and then monotonically decreasing, deviations of (2) from zero (in either direction) indicate an increasing opportunity to improve the value of the asset. Deviations can be positive or negative. Specifically, as (2) deviates from zero, the following equivalent interpretations are available:

- the marginal value (importance) of management action increases,

- the potential for ecosystem improvement increases,

- the deviation from desired ecosystem condition increases (higher values of $\mathrm{V}$ are desirable).

Equation (2) defines the marginal value of management (marginal value product of management) and it equivalently measures the deviation of the site condition from its desired condition with respect to any management variable $\left(\mathrm{M}_{\mathrm{i}}\right)$. If, for example, our site value is maximum when fully restored (FRCC 1), then it would be fully achieved only when (2) is satisfied across the set of Ms.

Initially specifying the problem with no management cost is equivalent to describing full restoration as a desirable condition and this is common in land and fire planning. Alternatively, addressing the net value of management requires introducing a marginal management cost. This is available in this framework, but it is unnecessary to demonstrate the contributions of this paper. Recognizing that costs matter, we will use (2) to assess alternative ecosystem conditions, but not to directly make resource allocation decisions.

The implications of (2) are key to solving our management problem of allocating management resources with respect to ecosystem value. Allocation of scarce management resources to improve ecosystem value typically requires knowledge of marginal values as shown by (2); not total value (1). Recognizing that assumptions regarding smoothness and linearity are required, we continue with a first approximation to addressing this elusive problem. We have now specified the condition for addressing the ponderosa pine versus sequoia restoration problem mentioned above with regard to FRCC. 


\section{The marginal value of fire management}

When fires occur on the landscape they produce a myriad of effects; some are improvements and may be restorative while others threaten valuable resources. The aim of fire management is to obtain the greatest overall net benefit (value change) from allocating fire management resources. In some instances fire management can encourage burning to obtain improvement of ecosystem values and in other situations fire management can be used to keep fire from spreading into resources that would be damaged. The fire management problem with regard to a desired ecosystem value can also be expressed in marginal terms through a system of implicit prices.

Specifically the value of fire management (VFM) can be specified as in (3) by an implicit price:

$$
\mathrm{VFM}_{\mathrm{i}}=\mathrm{VFM}_{\mathrm{i}}\left(\mathrm{RV}_{\mathrm{i}}, \mathrm{I}, \mathrm{EC}, \mathrm{B}\right)
$$

In (3), the value of fire management with respect to a particular resource such as the protection of property is specified by the subscript. For example, $\mathrm{RV}_{\mathrm{i}}$ denotes the value of $i^{\text {th }}$ resource, I denotes fire intensity, EC denotes the ecosystem condition (such as condition class, or FRCC) and B denotes the fire management budget. The marginal value of fire management with respect to managing a particular value (i) is denoted by the partial derivative as:

$$
\frac{\partial V F M_{i}}{\partial R V_{i}}=I P_{i}=M V P_{i}
$$

The marginal value of managing a particular resource (i) is defined as its implicit price $\mathrm{IP}_{\mathrm{i}}$ that is equivalent to the concept of marginal value product $\left(\mathrm{MVP}_{\mathrm{i}}\right)$.

Importantly from (2), the IP for a particular resource is equivalently the marginal value of fire management and the distance from desired fire management condition. Next, by combining information on a full range of marginal values (IPs) with fire probabilities across a landscape, we are positioned to measure the expected distance from desired fire management condition for different fire management strategies.

\section{Valuing fire management alternatives on a landscape}

Assessing the value of fire management across a landscape means combining the probability that any part of the landscape might burn with the marginal value of burning. This equivalently produces the expected marginal value of burning. This will be applied to each cell on the landscape. Summing across all of the cells in a landscape produces the expected deviation from the desired fire management condition for the landscape.

$$
\sum_{i} \sum_{j} P_{j} * M V P_{i, j}=\text { ExpDeviation }
$$


In (5), $\mathrm{P}_{\mathrm{j}}$ denotes the probability of the $\mathrm{j}^{\text {th }}$ cell burning and $\mathrm{IP}_{\mathrm{i}, \mathrm{j}}$ denotes the implicit prices summed across cell $\mathrm{j}$ and across all cells. This summation represents the expected deviation of the landscape from desired fire management condition (including all values). Once this metric is produced, management actions for fire protection or for restoration can be applied and compared. To the extent that management applications are fully effective, they change the cell MVP from the initial state where $\mathrm{IP}_{\mathrm{i}}=\mathrm{MVP}_{\mathrm{i}}$ to an MVP of zero. Summing the values again, after a management strategy has been applied will produce a lower deviation from desired fire management condition. Comparing the untreated deviations with post treatment deviations provides a metric of improvement to expected fire management condition. While the metric is used here to assess the post treatment landscape condition of alternative management strategies, it is not intended to be used to identify what should be done because it does not include enough information such as marginal cost (although it could).

\section{Improving the desired landscape condition}

Here we apply equation (5) to a forested landscape where fire management planning is critically engaged with a spectrum of human and ecosystem values. We quantify and show the effects of alternative planning strategies on the improvement of the desired fire management condition.

\subsection{The Catamount Study Site}

The Catamount Study Site is located in the state of Colorado approximately 20 miles west of Colorado Springs. The 40,000 hectare site straddles El Paso County on the east and Teller County on the west. The area is contained within the Pikes Peak Ranger District of the Pike-San Isabel National Forest. The USDA Forest Service manages 28,250 hectares and 11,717 hectares are primarily private land holdings [8]. Large mountain rages (Rampart Range) bound the area on the northeast and the north and south slopes of Pike's Peak are contained within the study area. These areas provide habitat for big horn sheep, elk and numerous other species of plants and animals. The study area is dominated by fire adapted forest vegetation predominantly comprised of ponderosa pine, aspen, Douglas-fir and limber pine with lesser amounts of lodgepole pine and spruce fir. The interior of the study site contains 11,927 hectares that have been designated for municipal watersheds through a series of congressional acts and cooperative agreements for the municipalities of Colorado Springs, Manitou Springs and Cascade Town Company [8]. These agreements have led to cooperative forest management strategies to protect the watershed reserves between the municipalities and the USDA Forest Service that focus on reducing fire hazard.

The Catamount site contains heavily developed properties along State Highway 24 to the north and the city of Colorado Springs borders the study area to the south. The Healthy Forest Restoration Act (HFRA) of 2003 provides an opportunity for these communities to address the challenges of living in a 
wildland-urban interface (WUI) by establishing Community Wildfire Protection Plans (CWPP). By implementing a CWPP, these communities are eligible for matching federal grants for fuel reduction projects. The collaboration of the communities with local and federal fire agencies resulted in the Ute Pass CWPP and the Teller County CWPP. A portion of the Teller County CWPP and almost the entire Ute Pass CWPP is contained within the study site.

The Catamount study site provides a combination of physical topography, wildlife, fire adapted forest, fire sensitive areas (watershed and WUI) and legislative initiatives representing the wide array of ecosystem, market and social concerns that fire managers and planners must consider when assessing alternative fuels management strategies on a desired fire management condition.

\subsection{Performing the landscape analysis}

The landscape analysis was generated using the strategic spatial management and planning system called STARFire. The analysis generates a baseline quantitative summary of the landscape relative to a desired fire management condition as defined in (5). The baseline analysis represents the current condition of the landscape relative to desired fire management condition. Planning scenarios are then introduced and evaluated relative to the baseline condition. The baseline analysis is represented by three core data sets: fire behaviour conditions, value information (IPs) and fire history. The first reflects the spatial fire characteristics of the study area. The second is used to estimate the value of fire effects as in (4); both beneficial and detrimental. The third is used to support estimations of ignition probability. Fire history information was provided by the USDA Forest Service, South Platte Ranger District Office.

Fire behaviour was estimated using the public domain software FlamMap from FIRE.org (a fire behaviour analysis program that computes potential fire behaviour characteristics over an entire landscape using constant weather and fuel moisture conditions). The resulting spread rate, fire intensity, maximum spread direction, and flame length calculations were provided to STARFire. The data used to run FlamMap were downloaded from LANDFIRE (an interagency vegetation, fire and fuel characteristics mapping program).

The MARS (Marginal Attribute Rate of Substitution) [9] valuation system was used to estimate the value of fire effects. MARS quantifies the fire-induced changes in value of resources. There are three components to the MARS evaluation that enable the system to address value change as per (3). The first part requires identifying resources where fire induces value change. The second identifies how the resources are affected by fire at different intensities/severity. The third identifies how the fire sensitive resources are affected by the ecosystem condition. Values assessed included: protection of property, boundary effects, municipal water, wildlife habitat, and timber types (including ponderosa pine, lodgepole pine, Douglas-fir and aspen). Figure 1 shows the spatial arrangement of three selected values: timber types, highly valued property (WUI) and watershed management areas, and sensitive wildlife habitat. 

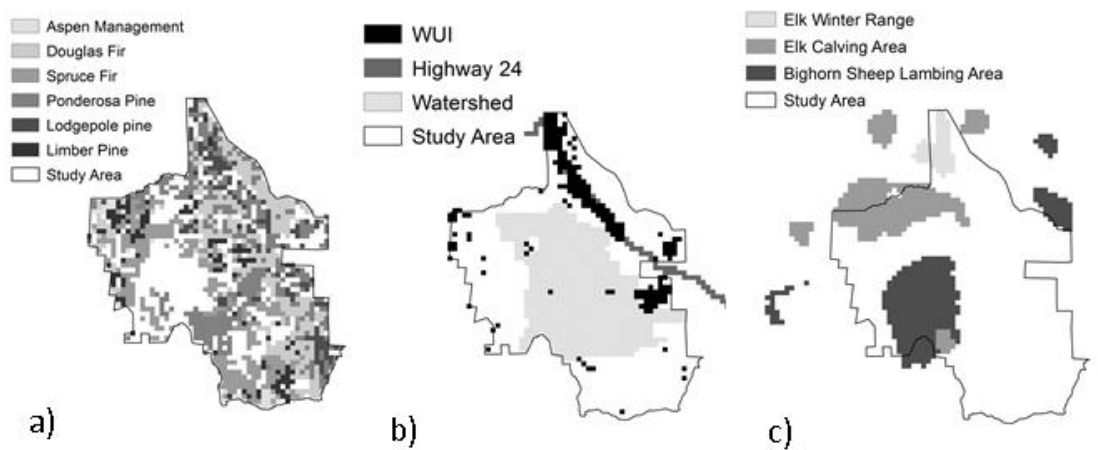

Figure 1: $\quad$ Spatial arrangement of selected fire management values (IPs). Panel a) shows major timber cover types, Panel b) shows human development and watershed and Panel c) shows wildlife habitat.

\section{Results: planning alternatives and desired fire condition}

The STARFire analysis was performed to assess the deviation from desired fire management condition for four planning scenarios:

1. Baseline (current condition).

2. High-level fuel treatment program.

3. High-level fuel treatment program and aggressive suppression program.

4. Low-level fuel treatment program.

The baseline provides a foundation for measuring the relative effectiveness of the three management programs under consideration. The baseline condition is shown in panel A of Figure 2. In each of the figures, the light or no shading indicates no deviation from desired condition (MVP $=0$, see (4) above). The Darker shading shows increasingly high deviations from the desired fire management condition (MVP $>0$ ). These are locations where the potential to benefit from active fire management through fuels treatment or suppression are the highest. Panel b) shows the landscape fire management condition for scenario 2: a high-level fuel treatment program. The locations of the fuel treatments are outlined in the figure and shown to have converted to a desired fire management condition ( $\mathrm{MVP}=0$ ). In some cells the fuel treatment was only partially successful. Panel c) displays the results for scenario 3: a high level of fuel treatment and an aggressive suppression program. In panel c) the dark grey outlines enclose the locations of fuel treatments and the black outlines enclose areas that have received suppression efforts. A low-level fuel treatment scenario was also analysed to reflect a low fuel budget allocation and it is not shown in the figure (scenario 4). 


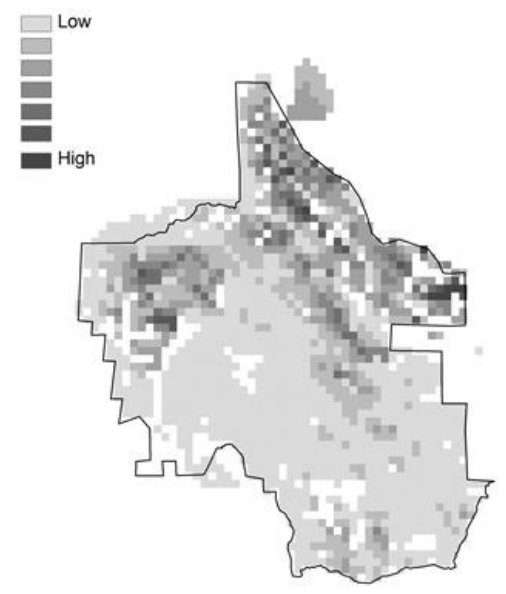

a) Scenario 1 - Baseline (current condition)

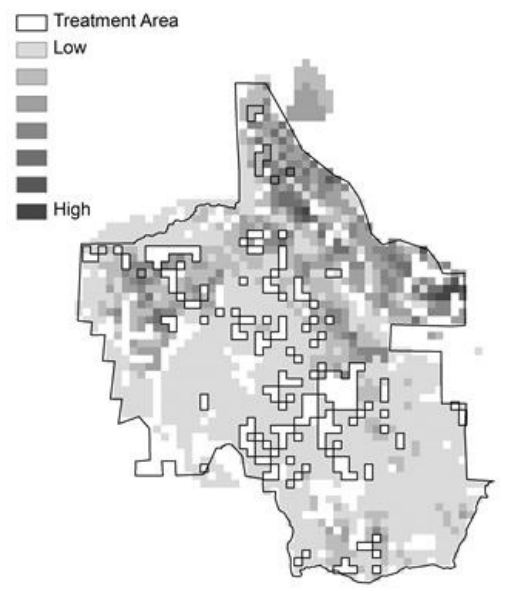

b) Scenario 2 - High-level fuel treatment program

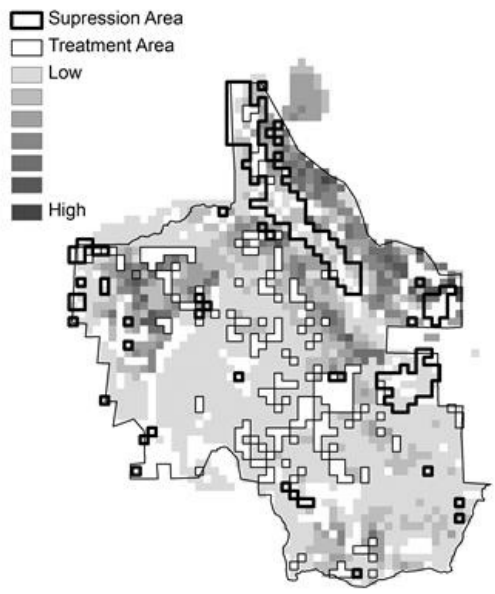

c) Scenario 3 - High-level fuel treatment program and aggressive suppression program

Figure 2: Landscape analysis map from the Catamount Study Site. Panel a) represents the baseline condition (no treatments). Panel b) represents the landscape after 4,608 hectares have received fuel treatments (treatments indicated by dark grey outline) and panel c) represents the landscape after 4,608 hectares of fuel treatments have been completed and 2,165 hectares have received suppression efforts (suppression locations indicated by black outline). 


\section{Discussion of alternatives relative to desired fire condition}

The baseline analysis (panel a) contains very little 'white' area indicating that the majority of the landscape has potential to benefit from active fire management. In scenarios 2 and 3 (Figure 3, panels b and c) the majority of the areas that received fuel treatments have changed from a darker colour (areas that have the potential for ecosystem improvement) to a white colour (desired fire management condition). The ecosystem benefit from treating these areas has been accomplished. In scenario 3 (panel b), there are several areas at the north end of the site that remain dark within the fuel treatment locations. These WUI (property) cells were selected by the STARFire fuel treatment optimizer as locations that would most benefit from hazard fuel reduction. While they are lighter they are not white as suppression is also required for full protection.

Combining an aggressive suppression strategy with fuel treatments (scenario 3) on the same cell generates ecosystem benefit and hazard fuel reduction. The combined benefit brings the cell to a desired condition as indicated by the white colour. Under this scenario there are areas in the north section of the study site that have received suppression effort and no fuel treatments. These areas remain a darker colour as suppression effort did not achieve the full ecosystem benefit as compared to fuel treatments effort. Areas that only contain values that benefit from suppression (represented by cells on the west boundary of the study site) achieve the full effect of the suppression effort and are changed to white. The fuel treatments completed in scenario 2 (panel b) changed a large collection of cells to a desired fire management condition, the combination of fuel treatment and suppression in scenario 3 (panel c) changed the largest number of cells to white.

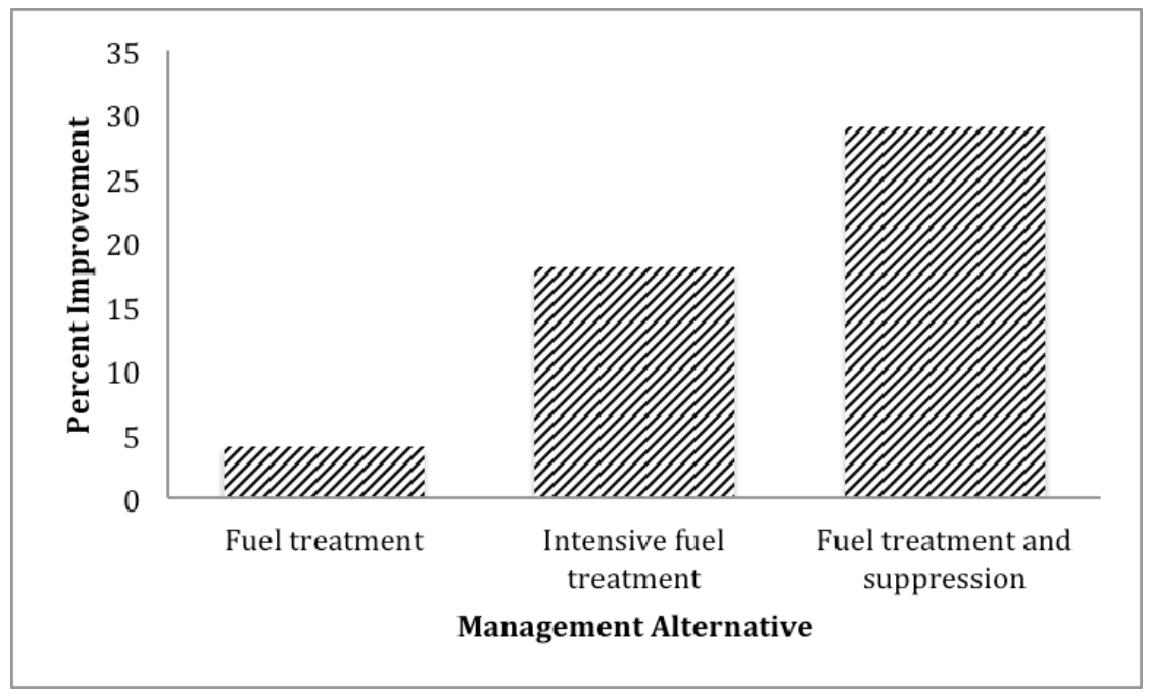

Figure 3: Percentage improvement over the baseline condition for each management alternative. 
While the maps shown in Figure 3 are valuable in showing where management variables were effective in improving the condition of the landscape, they need to be combined with summary metrics of improvement to identify the overall improvement in value. Applying equation (5) across the study site enables us to identify the amount of valued improvement or movement to a desired fire management condition from each management alternative. These results are shown in Figure 3. In Figure 3, the baseline condition is indicated by the horizontal axis and the bars show the percentage improvement relative to the baseline scenario. The first bar shows a five percent improvement obtained from a low-level fuel treatment program. A high-level fuel treatment program improves by almost 20 percent and combining this with an aggressive suppression program generated improvement relative to the baseline by almost 30 percentage points.

\section{Conclusions}

This study shows how the value of management variables can be assessed in a modern ecosystem management framework at the landscape level. By relying on marginal analysis, instead of metrics of total value, we estimated the relative value of alternative fire management strategies on a complex landscape. This prominent site near the city of Colorado Springs, Colorado includes a wide range of values to improve or protect through fire management alternatives. These values include timber, municipal watershed, wildlife and the protection of property. This fire-prone area with high potential to benefit from fire management receives much attention from authorities that can potentially benefit from such an analysis.

Classical economic metrics based on commercial timber production are too narrow for today's management of ecosystem values. However, their roots in sound marginal analysis have important applicability. Recent biophysical metrics associated with the restoration paradigm, such as FRCC, are also too narrow to guide sound resource allocation decisions. Recognizing that total value is impractical to estimate in an ecosystem management context, we directly applied a marginalist approach. By defining what is valuable to protect or improve through fire management and how valuable, marginal analysis can incorporate the full set of ecosystem and commercial values. Importantly, it can focus on how the marginal fire management effort can improve the desired fire management condition. In a broader sense, such marginal analysis is useful in assessing fire management planning alternatives at the landscape level.

\section{References}

[1] Faustmann, M. Berchnung des Werthes welchen Waldbooden sowie noch night haubare Holzbestande fur die Waldwirtchaft besitzen. Allgermeine Forts and Jagd-Zeitung. 25:441-445, 1849. (English translation in Linnart, W. and M. Gane. Martin Faustmann and the evolution of discounted cash flow. Commonwealth Forestry Institute Paper 42. 1968. 
[2] Samuelson, P.A. Economics of forestry in an evolving society. Economic Inquiry. 14, pp.466-492, 1976.

[3] Committee of Scientists. Sustaining the People's Lands: Recommendations for Stewardship of the National Forests and Grasslands in the Next Century, a report to the Secretary of Agriculture and to the Chief of the Forest Service. Washington D.C.: U.S. Department of Agriculture, pp.34-35, March 15, 1999.

[4] Hardy, C.C., Schmidt, K.M., Menakis, J.M., and N.R. Samson. Spatial data for national fire planning and fuel management. International Journal of Wildland Fire. 10, pp.353-372, 2001.

[5] Hann, W.J. and D.L. Bunnell. Fire and land management planning and implementation across multiple landscapes. International Journal of Wildland Fire. 10. 2001.

[6] Mills, T.J, and P. Flowers. Wildfire impacts on the present net value of timber stands: illustrations in the Northern Rocky Mountains. Forest Science (32):3. pp.707-724. 1986.

[7] Samuelson, P. A., The Pure Theory of Public Expenditure. Review of Economics and Statistics, 36, pp.387-389, 1954.

[8] USDA Forest Service. Catamount Landscape Assessment. Pikes Peak Ranger District. Pike and San Isabel National Forests. Prepared by Continuing Education in Ecosystem Management, Module XIV. June 2-13, 2008. Woodland Park, CO, 2008.

[9] Rideout, D. B., Ziesler, P. S., Kling, R., Loomis, J. B. \& Botti, S. J., Estimating rates of substitution for protecting values at risk for initial attack planning and budgeting. Forest Policy and Economics, 10, pp.205-219, 2008. 